\title{
On Overseas Chinese Teaching from the Perspective of Intercultural Communication
}

Zhiwei, $\mathbf{G u}^{1}$

'Confucius Institute, Egerton
University, Nakuru, Kenya

Email:1316478175@qq.com

Licensed:

This work is licensed under a Creative Commons Attribution 4.0 License.

Keywords:

Teaching Chinese as a foreign

Language

Intercultural communication

Communication barriers

Communicative competence.

\begin{abstract}
With the continuous and rapid development of China's economy, Chinese has become one of the most important languages in the world, and more and more foreigners begin to learn Chinese. For Chinese teachers who teach Chinese as a foreign language, the teaching process is also a cross-cultural communication process. The Cultivation of Intercultural Communicative Competence of teachers of Chinese as a foreign Language is very important. In this process, Chinese teachers should not only have good knowledge of the language and respect the cultural awareness of both sides, but also pay attention to certain communication strategies. Only in this way can the cross-cultural teaching be carried out smoothly and a good teaching effect can be achieved.
\end{abstract}

\section{Introduction}

In today's world, due to the increasing degree of economic globalization, countries are striving to communicate and cooperate with each other, which inevitably involve cross-cultural communication activities. Intercultural communication refers to the communication between people of different cultural backgrounds. It refers to the communication between native speakers and non-native speakers, as well as between people with different languages and cultural backgrounds. Intercultural communication is different from ordinary communication, because intercultural communication transcends the restriction of different cultures (Wang, 2005). In the process of communication, cultural conflicts often arise because of the differences in thinking habits and cultural backgrounds of people in different cultures, which leads to communication obstacles, thus resulting in communication failure. Therefore, in order to avoid these situations, the communicator must improve his cross-cultural communicative competence.

The necessity of improving the intercultural communicative competence of TCFL teachers lies in its need to develop the history of TCFL. The teaching of Chinese as a foreign language usually refers to the teaching of Chinese to foreigners and overseas Chinese who are not using Chinese as the first language. Therefore, intercultural communication factors must be embedded in the teaching of Chinese as a foreign language (Liu \& $\mathrm{Li}, 2003)$. It is also because the teachers of Chinese as a foreign language come into contact with students from different countries. They speak different mother tongues, having different cultures, different ages, different characters, and there are also great differences in reception ability of Chinese language. Therefore, the teaching process of Chinese as a foreign language will inevitably lead to the collision and friction between the different languages and cultures in the process of teaching (Lius \& Yue, 2005).

\section{The Training of Chinese Teachers Communicative Competence}

As a TCFL teacher, whether he/she teaches Chinese as a foreign language or teaches Chinese in a foreign country, it is a cross-cultural communication process first, then a process of teaching Chinese. The following aspects need to be observed:

\subsection{TCFL Teachers Should Have the Language Competence of Focusing on Cross-Cultural Communication}

This language ability requires teachers to be able to use a foreign language or several foreign languages simply, to be familiar with comparative linguistics, and to teach Chinese in a targeted way in cross-cultural language comparison. That is, to overcome the language barrier of students, promote trust between students and teachers, and gradually build up Chinese way of thinking and accept the teacher's class mode.

As for the target language itself, TCLF teachers need to pay attention to two aspects: language rules and language use. Language rules refer to phonetics, vocabulary, grammar, etc. Chinese teachers should master the ability of successful teaching by means of limited language and make conscious use of the "universal communicative language" which are suitable for foreign students, because they are confronted with foreign students, so their teaching language should be different from the teacher's daily language in a certain degree. 
In the aspect of cross-cultural pragmatics, TCFL teachers should pay attention to the accurate expression of language and the using context of different languages. Because countries with different cultures have their own unique rules of language use, there are their own appropriate standards. A language expression that conforms to the rules of the language will not serve the purpose of conveying information or even cause misunderstanding when it is used in inappropriate situations (Wangs, 1994).

\subsection{Understanding and Respecting Each Other's Cultures}

A qualified TCFL teacher should not only have the knowledge of pure linguistics, but also have the relevant cultural knowledge. Because of the common cultural background, cross-cultural communication will not create communication obstacles because of the cultural problems. Intercultural communication takes place between different cultures. the similarities between the two cultures facilitate the interaction and communication between the two cultures, and the differences may lead to the bias and obstacles of language understanding and application because of the differences. The differences between different cultures are unacceptable by both sides. The differences between different cultures could lead to contradictions and even conflicts. As a TCFL teacher, we must not comment on which side has the better culture or the more beautiful language, instead, we must be aware of the differences between different cultures, actively adjust our mentality, avoid negative avoidances, reduce frustration and adopt a positive attitude in teaching (Yu, 1998).

In the cultural teaching of Chinese as a foreign language, teachers should first introduce Chinese culture. For example, when foreign students say that it is barbarous and strange for Chinese people to eat dog's meat, TCFL teachers can never agree with their opinions, but they should explain to them that different peoples have different cultures. Since ancient times, the Han people have taken a contemptuous attitude towards dogs, as we can see from the Chinese language, such as the idiom“狼心狗肺” (wolf's heart and dog's lung, heartless ), “狗仗人势”（be a dog bullying others under the protection of a powerful person）, “猪狗不如”（worse than pigs and dogs) and so on. It is also because of the cultural differences that foreign students praise their teachers saying "He runs as fast as a dog." Second, they should have a general knowledge of the foreign students' culture, at least which country the students come from, their social system, religious beliefs, eating taboos, customs and habits, etc. This is not only for the purpose of training the foreign students to master and use Chinese accurately, but also to create a good classroom atmosphere, so that the class teaching can go on smoothly. It is also the embodiment of the equality consciousness and the Chinese culture in cross-cultural communication to respect the other countries' cultures. It is not only a fine tradition of Chinese culture, but also a correct attitude that we TCFL teachers should adopt in cross-cultural communication that all things are parallel and not contrary to each other. We should treat different cultures with an open mind, carry forward Chinese culture with a rational attitude, and strive to improve our cross-cultural communication ability in teaching Chinese to foreign learners.

\subsection{TCFL Teachers Should Master Some Communication Strategies in Cross-Cultural Communication}

This is an integral part of his cross-cultural communicative competence. "Communicative Strategy" refers to the measures taken by the communicator according to the actual situation, i.e., when the foreign learners study abroad in China, many cases in reality may be different from what they have thought, which makes them tired of studying and living in China and cause anxiety and confusion. When facing various kinds of students, TCFL teachers must use feasible strategies and methods to make the students come out from their maladjusted state as soon as possible and form good learning and living habits. (Huang \& Liu, 1999) The cross-cultural communication strategies mentioned herein mainly include three aspects: avoidance, coordination and tolerance.

\section{(1) Avoidance}

Avoidence includes avoid mentioning, silence, obscurity or a change of subject matter, etc. In the course of communication between Chinese teachers and foreign students, both sides often talk about some sensitive topics in each other's culture, At this point, the teacher can pretend not to understand, avoid talking, or use his humorous discourse to digress from the topic and change the uncomfortable state of communication as soon as possible. However, during the communication if students violate the cultural taboo, to some extent it has hurt the national esteem of teachers, teachers should tell the students in a tactful way, rather than blindly agree.

\section{(2) Coordination}

Intercultural communication is a dynamic process of two-way coordination. In this process, the two parties must adopt various strategies to coordinate, understand the other party's speech, respond to the other's words, adjust their participation in the conversation, and try to adjust the other party's participation so that the conversation can proceed smoothly and finally achieve the goal of communication (Liuu, 2000). To improve the intercultural communicative competence does not mean it requires teachers to be proficient in many foreign languages and be able to communicate with students in many countries smoothly through language, but it asks teachers to infect students through their own characteristic words and deeds, the socalled characteristic words and deeds are what we call "coordinating strategies". 
In terms of communication style, teachers are the main factor in this communicative behavior. It is true that the objects of Chinese teaching are adults who have certain knowledge basis, however, in the aspect of Chinese learning, they can't get rid of their intermediary state in a certain period of time. The communication between teachers and students is a process of cross-cultural communication in a harmonious state to a great extent. As far as communication content is concerned, because of the cultural differences between Chinese teachers and foreign students, communication barriers will inevitably arise. In order to avoid communication obstacles, teachers must use effective coordination strategies.

\section{(3) Tolerance}

In intercultural communication, the two parties usually use their own way and discipline of talking to judge the other side's way of talking, This is one of the main causes for the conflict. Therefore, CTFL teachers should be prepared in advance to tolerate students, the higher the tolerance is, the less likely you are to have a communication barrier, and the more likely it is to improve the quality of communication (Yuan, 2003). Except for some teachers who teach Chinese in foreign countries, most of the TCFL teachers are engaged in teaching Chinese as a foreign language at home. Therefore, they are often in contact with students from different countries, apart from Korean students, there are students from the United States, Britain and Japan. Because some students have their own way of thinking and behavior, thus make the Chinese teachers feel uncomfortable. In addition, when some students make mistakes, TCFL teachers should also give priority to criticism and corrections, infecting students with their own sincere words and gradually awaken the students to realize their own mistakes. If teachers can't take a tolerant attitude towards these things, it will lead to the failure of communication between teachers and students, Students' aversion to teachers may also lead to dull Chinese learning, Eventually, they will lose interest in Chinese learning.

\section{Conclusion}

At present, the internationalization of cross-cultural communication and education has become a big trend, and teaching Chinese as a foreign language is the outcome of this trend. Teaching Chinese as a Foreign Language (TCFL) is a special teaching post in which every TCFL teacher faces foreign students who come from all over the world and have a deep yearning for Chinese culture, In order to deal with the problem of cross-cultural interpersonal relationship between students and students, Chinese teachers of foreign languages must develop their abilities in terms of their language quality, attitude to both cultures and specific communication strategies. This is the only way to deal with the problem of cross-cultural communication, We should constantly improve our cross-cultural communicative competence so that it can better match the teaching work done by Chinese teachers as a foreign language. Only in this way can our teaching of Chinese as a foreign language attract more students from other countries to come to China to learn Chinese and cultivate more and better worldwide Chinese language talents.

\section{References}

Huang, J., \& Liu, Y. (1999). Theory and Methods in Teaching Chinese as a Foreign Language. Peking University Press.

Liu, S., \& Li, Z. (2003). Teaching Chinese as a Foreign Language and Cross-cultural Studies. Journal of Tunnan Normal University(1).

Lius, L., \& Yue, G. (2005). On Cross-cultural Issues in Teaching Chinese as a Foreign Language. China Science and Technology Information(2).

Liuu, M. (2000). An Introduction to Pedagogy of Chinese as a Foreign Language. Beijing Language and Culture University Press.

Wang, C. (2005). Cultural Differences and Improvement of Intercultural Communicative Competence. Journal of Shandong Institute of Education(1).

Wangs, K. (1994). Multifaceted nature of teaching Chinese as a foreign language and cross-cultural issues. Journal of Beijing Normal University Social Sciences(6).

Yu, Y. (1998). Research on Chinese Culture and Teaching Chinese as a Foreign Language Teaching Research Particles. Yunnan National Publishing House.

Yuan, X. (2003). Cross-cultural Communication and Foreign Language Teaching. Journal of Yunnan Normal University(2). 